\title{
EL MESTRE CANALETES I «EL CUENTO DEL FORMIGÓ» Susana Canals Boix
}

A totes aquelles persones que han fet realitat el meu somni.

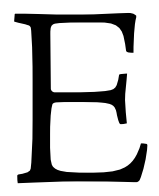

1 sistema educatiu ha evolucionat d'acord amb els canvis socials i polítics de la societat. Així doncs, si fem una ullada pel segle XIX i bona part del XX, trobem una època en la qual l'accés a l'educació era difícil per a una bona part de la població, sobretot la rural. Cal recordar que en el segle XIX l'ensenyança primària era regulada per l'Estat i aquest transferia a l'església una part important de les competències i les responsabilitats. Mitjançant la Llei Moyano d'Instrucció Pública de 1857 es va instaurar un model que donava importància als estudis de ciències i establia l'ensenyament de primària obligatori des dels sis als nou anys. Després, fou Francisco Giner de los Ríos qui va encapçalar la protesta en defensa de la llibertat de càtedra; i va fundar la Institució Lliure d'Ensenyança. L'ensenyament de primària durant tot el segle XIX va ser a càrrec dels municipis, i els mestres no començaren a ser remunerats per l'Estat fins al 1901, amb retards, i solament en dos terços del seu sou, de manera que les famílies havien d'aportar la resta.

Pel que fa a la situació cultural i econòmica, al segle XIX la major part de la població espanyola vivia installlada en una economia d'autoabastiment i de pobresa, i el grau d'analfabetisme era prou gran. El municipi d'Elx va iniciar la industrialització a partir de l'últim quart del segle XIX, sobre la base de la industria espardenyera i les indústries que en depenen, com ara la tèxtil, i a partir de l'evolució d'antigues artesanies. En aquests sectors la preocupació per l'ensenyament es va posar de manifest amb major força, mentre que al camp no hi havia la mateixa preocupació. Per als empresaris industrials era important que els treballadors saberen llegir, escriure i de comptes, però per als propietaris rurals tradicionals l'alfabetització dels llauradors podia ser, fins i tot, un inconvenient. 
Aquest és el context en què va nàixer Josep Canals $\mathrm{i}$ Jiménez, l'any 1898 a Elx, al si d'una modesta família de llauradors. La seua vida estigué sempre lligada als llibres i van ser més de seixanta els anys que va dedicar a l'ensenyança. Popularment era conegut com el mestre Canaletes, i es va preocupar per culturalitzar la gent del camp d'Elx en una època en la qual la situació econòmica i educativa no feia fàcil l'accés a l'educació.

La situació de l'educació a la ciutat d'Elx al començament del segle XX era marcada per la mancança de mestres i l'escassa preparació. Possiblement, la formació dels mestres era insuficient $\mathrm{i}$ altres no tenien la titulació exigida per a desenvolupar aquesta tasca. Actualment, Elx és una ciutat de més de 200.000 mil habitants, però l'any 1900 Elx era un poble amb uns 20.000 habitants, la meitat dels quals vivien a les partides rurals i l'altra meitat al centre urbà. A més a més, el $82 \%$ de la població il.licitana era analfabeta i no sabia llegir ni escriure. Això representava set punts percentuals per damunt de la mitjana espanyola. Els adults ja eren majors per a assistir a l'escola i els xiquets havien de treballar als vuit anys, si no abans. I és que els assalariats, tant a la ciutat com al camp, havien de suportar unes jornades abusives de treball a canvi d'un sou de misèria. Aquesta era una de les causes de l'analfabetisme, ja que des de la més tendra infantesa, xiquets $i$ xiquetes eren posats a treballar per a ajudar al sosteniment de la família. En definitiva, l'assistència a l'escola depenia principalment de la voluntat de les famílies i de les possibilitats econòmiques. També la ubicació dels centres educatius condicionava l'assistència, perquè era el mestre qui solia posar la pròpia casa com a espai escolar. A més a més, la part principal del sou del mestre procedia dels diners que l'alumnat li entregava.

El mestre Canaletes fou un de tants infants que començaren a treballar des de molt menuts; però, les ganes d'aprendre fomentaren la seua afició per la lectura. Als vuit anys, o abans, començà a treballar a les salines de Santa Pola per colllaborar en el manteniment de la família. També destinava part del seu sou a la formació: aprengué música i, com a instrumentista, es defensava amb la bandúrria. Era un home autodidacta i els llibres l'acompanyaven allà on anava. Durant el temps de descans, a les salines, aprofitava per a llegir, estudiar i fer deures. Després de les llargues jornades de treball, a la nit, Josep encara trobava ganes d'estudiar 
i es desplaçava al poble d'Elx per rebre lliçó. Primer ho feia a peu; després, en bicicleta.

L'escola il-licitana continuava acomodant-se a les millores de la Llei Moyano, i el nombre d'escoles augmentava progressivament, encara que algunes en unes condicions higièniques pèssimes. L'any 1910 Elx tenia vora 44.900 habitants, entre la ciutat i el camp, i la situació escolar cada vegada resultava més preocupant. Durant aquesta dècada i la següent s'incuba el projecte de les Escoles Graduades, mentre que la resta de centres escolars continuava amb deficiències i mala qualitat de materials. Fou gràcies a la Junta d'Inspecció Pública que es crearen onze noves escoles, tant a la ciutat com a les partides. No obstant això, algunes de les escoles eren tancades per no complir les condicions adequades.

$\mathrm{Al}$ voltant dels 17 o 18 anys, en Josep Canals començà a donar lliçó per les cases, malgrat que no tenia estudis reconeguts per a desenvolupar la tasca de mestre. I és que d'aquesta manera Josep trobà una faena que el feia sentir millor, compartint el seu saber amb els seus veïns $i$ formant-los en els estudis. Però com hem vist, l'educació no era a l'abast de tots i la remuneració econòmica que rebien els mestres no era suficient, de manera que quan, al cap d'uns anys va contraure matrimoni amb Maria Blasco, hagué de canviar de treball, perquè el de l'educació no els permetia subsistir. La situació econòmica no era gens favorable i les coses no anaven bé. Davant d'aquesta delicada situació Josep va emigrar a França i després al Marroc. Però prompte va tornar a la seua terra nadiua, prop de la seua família.

Aleshores, quan tornà de l'estranger, Josep va reprendre la tasca de donar classes. L'educació continuava presentant problemes, a pesar que l'administració municipal treballava per resoldre'ls. Els escassos centres educatius rurals eren deficitaris i el nombre d'infants sense escolaritzar era elevat, ja que havien de realitzar tasques agrícoles. Les famílies del camp il-licità optaven perquè el mestre visitara l'alumne en acabar la jornada de treball. I el mestre Canaletes es va especialitzar en aquesta necessitat. A més a més, la formació acadèmica s'ampliava contínuament gràcies als canvis produïts en el sistema educatiu encapçalats per Giner de los Rios. Fins i tot, va aconseguir complementar estudis per corres- 
pondència en la Institución Especial Libre de Enseñanza Profesional de Badajoz.

Durant la II República, el sistema educatiu es proposava la igualtat davant l'escola de tots els xiquets com un primer pas per a la transformació social. També, amb la promulgació del decret del 21 de maig de 1931, es va prohibir donar lliçó a tots aquells que no tingueren el corresponent títol. Per tant, els centres escolars van haver de fer una reorganització del professorat. Aquell mateix mes de maig de 1931 el Ministeri va concedir la creació de tretze escoles, deu de les quals ubicades al camp, concretament a les partides de la Baia, la Foia, Matola, Daimés, Puçol, Torrellano Baix, Algorós, Maitino, Altabix i Jubalcoi; i el 1936 es va construir el primer grup escolar del camp d'Elx, a la partida d'Atzavares Baix.

No obstant això, en quasi totes les partides rurals d'Elx hi havia la figura del mestre que anava casa per casa donant lliçó a aquells xiquets que no tenien la possibilitat d'anar a l'escola. D'aquesta manera, els mestres rurals feren una labor importantíssima, ja que supliren les deficiències del sistema educatiu vigent en aquella època. A la Baia fou el Mestre Canaletes, juntament amb el mestre Galima, amic i veí, un dels mestres que recorrien la pedania; la Baia, Asprella, la Foia, Perleta, Valverde i Maitino són algunes de les pedanies que recorria amb la bicicleta i la cartera de cuir. Un dia anava per la Baia, la Foia i Asprella; i el dia següent el dedicava a Valverde, Perleta i Maitino. Entre els dos recorreguts, tenia al voltant de cent alumnes, i feia prop de 50 lliçons al dia. A més a més, Canaletes rebia a sa casa, de nit i al llarg de la setmana, una trentena de xiquets. I finalitzava la jornada donant lliçó als seus cinc fills.

Alguns alumnes als quals donava lliçó el mestre Josep Canals eren joves que, malgrat que havien estat escolaritzats, abandonaren els estudis primaris per les necessitats econòmiques de les famílies. Per tant, quan aquests joves es plantejaven obtenir el certificat d'estudis primaris per continuar la formació, era el Mestre Canaletes qui els preparava perquè pogueren examinar-se a les Escoles Graduades d'Elx. Altres alumnes necessitaven una ensenyança específica dirigida a l'aprenentatge d'una professió (obrer, fuster, etc.), i era aquest mestre qui tenia la saviesa i la preparació necessària per a transmetre als alumnes tot allò que necessita- 
rien per a realitzar el treball especialitzat, com ara cubicar un pou, mesurar una superfície, etc.

També el mestre Canaletes va conrear el vers i la prosa, i va escriure poemes i contes en to humorístic, i d'altres seriosos. Alguns dels seus escrits van ser publicats en El Tio Cuc, El Obrero i altres publicacions il.licitanes. Perquè, tot i que el mestre Josep Canals no era polític, es mostrava una mica revolucionari en les reivindicacions dels treballadors, $\mathrm{i}$ no dubtava a exposar les seues opinions.

Mitjançant una publicació, segurament en El Tio Cuc, el Mestre Canaletes va popularitzar «El conte de la formiga» o, com ell el titulava, «El cuento del formigó». Es tracta d'un relat escrit en valencià, i que en la època de la República fou molt comentat, ja que constituïa una crítica als polítics del moment.

Josep Antoni Canals Sempere, nét del Mestre Canaletes, conserva l'esmentat relat, escrit pel seu avi de pròpia mà. En facilitem, tot seguit, la transcripció de tan simbòlic document, tot respectant-ne la grafia prefabriana del manuscrit:

\author{
El cuento del Formigó \\ Siga el de Martin Sarmiento \\ o el que siga; què se yo? \\ Però veig tan bona unió, \\ que vaig a dir-vos un cuento \\ "El Cuento del Formigó" \\ A la sombra de una torre \\ habitava un formigó \\ que no lograva ocasió \\ de estar al sol sense córre[r] \\ sempre una bona extensió: \\ Es el dir; li molestava \\ perquè el sol $\mathrm{p}[\mathrm{er}]$ a tots ha eixit \\ i el animalet pensava: \\ Sóc tant insignificant \\ $\mathrm{p}$ [er] a una torre tant grandota \\ que el meu bulto no se nota; \\ pero enca $[\mathrm{r}]$ a caurà pegant \\ més voltes que una pilota
}


$i$ estant un rato pensant

pasejant-se per allí

cachá el cabet i sén va

i al cap de un mont torná

i de formigons per fi

en portá una milloná:

Tots arribaren pasmats

encantats mirant la torre

$i$ alguns desesperats

al punt de arrancar a corre

i posar-se a fer forats;

pero el mestre digué:

(que era aquell formigonet)

Espereu-vos un poquet

que el tantegem primer bé

i ni chut... tot el món quiet.

Un fardacho molt guasó

que del sol casi borracho

se le arisava el mustacho

pasá prop del formigó

Diu este: ¡Señor fardacho!

¿No te més educació

que pasar en el cap cacho

sense més salutació?

Contesta en guasa el fardacho:

¿Saludar yo a un formigó?

¿Haurá rasa més roina?

(Li diu anant dret a ell)

Se aparte de aquí tio vell

sino el faig a una quina

i se deixa aquí la pell.

¡Ja ja ja! Fer a una quina

els formigons a un fardacho.

¡Veste-ne burro! ¡Sarnacho!

I els atres des de la esquina

veient riure al amigacho

$i$ estos notant mala escena

quant arisava el mustacho

se li aganchen de la esquena

$i$ fent a un polvo al fardacho

se posen a fer faena.

I a la volta dels set añs 


\title{
Revista de Filologia
}

\author{
quant este cuento termina, \\ era tant fonda la mina \\ que cau en els soterranis \\ fent-se la torre a una quina. \\ De manera que la unió \\ es la força tant terrible \\ que en ella es fijí que no \\ se troba res imposible \\ Feu com este formigó!
}

Quan va esclatar la Guerra Civil, la societat il-licitana es va veure alterada. Però, encara que l'educació continuava sent una qüestió pendent de tractar, els problemes econòmics del moment impediren continuar el programa d'escolarització rural. A més a més, durant el franquisme el sistema educatiu i la societat espanyola van experimentar un canvi radical, i va decréixer el ritme de creació d'escoles. El mestre Josep Canals va abandonar la faena de mestre ja que estigué al front, amb el seu fill. Allí, de vegades, ajudava els companys que no sabien de lletres a escriure les correspondències per als familiars; i els ensenyava, un poquet, a llegir i a escriure. Després i durant el període de la dictadura, ell i la seua família, sofriren nombroses repressions a causa de la seua ideologia d'esquerres: $\mathrm{i}$ fou tancat en presó més d'una vegada per ser considerat roget. També i per la seua ideologia durant aquesta època, el mestre Canaletes no va poder fer realitat un dels seus somnis: publicar un llibre.

Ja en la segona meitat del segle XX es va reprendre el camí per pal.liar les mancances existents i posar així fi al dèficit de centres educatius, especialment els de primària. Això no obstant, a les zones rurals continuava vigent el problema de l'escolarització, i el mestre Canaletes continuava preparant els alumnes perquè obtingueren els estudis primaris. També els mètodes pedagògics estaven experimentant canvis, malgrat que fou un procés lent. Amb el decret de 1958, van aparèixer les normes específiques per als textos de totes les ensenyances i la incorporació dels esquemes de l'ensenyament actiu. I és en finalitzar la dècada dels cinquanta quan es veu un canvi substancial: hi ha escoles netes i assolellades, es parla de menjadors, biblioteques, laboratoris, instal-lacions esportives, etc. 
Ja en els seixanta, la transformació de la joventut - sobretot personal- era sorprenent. El 1965 es va promulgar una llei per a millorar la formació del professorat de Magisteri, i l'any 1970 es va promulgar la Llei General d'Educació (Llei Villar Palasí) que pretenia aconseguir l'assessorament dels professionals en l'actuació ministerial, per bé que la vigència encara de l'autoritarisme franquista topava amb l'esperit d'obertura de la llei. Durant aquest darrer període, Elx continuava fent un considerable esforç per estar a l'altura de les circumstàncies que apuntaven cap al progrés, i es van construir nombrosos grups escolars a la ciutat $\mathrm{i}$ a les partides rurals. En la dècada dels 70 , amb un sistema educatiu evolucionat en el qual tothom podia accedir a l'educació, una mica cansat pels entrebancs de la vida en Josep Canals deixà de donar lliçó. Al març del 1985 els diaris de la ciutat d'Elx es van fer ressò de la mort: amb ell desapareixia un dels últims mestres rurals del camp d'Elx.

Però la figura del Mestre Canaletes, encara avui, continua viva en bona part del camp d'Elx. Com a exemple trobem l'homenatge que la partida rural de Perleta va fer a Josep Canals i Jiménez, posant al seu collegi el nom de Mestre Canaletes, en memòria i reconeixement a la trajectòria com a mestre. El collegi adoptà com a emblema un llibre obert, i sobre aquest una bicicleta amb figura humana i una cartera, elements que recorden aquell mestre que recorria amb aquest mitjà de transport el camp d'Elx per fer lliçons als infants que en necessitaven. També la partida rural de la Baia va retre, recentment, homenatge al mestre Canaletes posant el seu nom a un carrer.

El mestre Canaletes va lluitar per allò que considerava important. I també per sobreviure en una època difícil i amb una professió poc remunerada. Va ser un home que destacà per la seua labor; i fou protagonista, víctima, heroi i emblema d'un període històric i unes circumstàncies educatives que ben mereixen ser testimoniades i recordades. 